\title{
Characterization of dynamic wireless body area network channels during walking
}

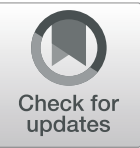

Marshed Mohamed $^{1 *}$ (D), Wout Joseph², Günter Vermeeren², Emmeric Tanghe ${ }^{2}$ and Michael Cheffena ${ }^{1}$

\begin{abstract}
In this work, finite-difference time-domain was used for the investigation of dynamic wireless body area network channel characteristics during walking, thus accounting for dynamic aspects and body postures. This involves the study of on-body, off-body, and body-to-body communication in an empty environment, at the center frequency of $2.45 \mathrm{GHz}$. The channels were investigated in terms of fade variation and their corresponding amplitude distributions. For on-body channels, the fade variation was found to be periodic, with larger fade variations for the channels involving the nodes at the hand and thigh. For off-body and body-to-body channels, channels with the absence of line of sight experienced constructive and destructive interference as the distance between the end nodes changes, resulting in larger fade variations. For the amplitude distribution of the channels, a multivariate normal distribution was considered. The distribution has the capability of modeling channels jointly which makes it easier for network analysis and was considered because of the significant correlation between the channels. The resulting estimated multivariate distributions fit well with the simulated data, for on-body, off-body, and body-to-body channels.
\end{abstract}

Keywords: Fading channels, On-body communication, Off-body communication, Body-to-body communication, Wireless body area network

\section{Introduction}

In recent years, there has been substantial research on wireless body area networks (WBANs) due to their potential applications in areas involving monitoring and transmission of human physiological data, such as health monitoring and sports activities. The communication could involve the transmission between nodes mounted on the human body realizing an on-body network, between an on-body network and a node away from the human body (external node) acting as an access point realizing an offbody network [1], and between two on-body networks realizing a body-to-body network. These kinds of networks require a low-power communication approach due to their need for long battery life and the close proximity of body surface nodes to human tissue. In addition to this challenge, the networks are subjected to varying signal shadowing caused by relative human body orientation between the communicating nodes which vary with the human body movement. These challenges make

\footnotetext{
*Correspondence: marshed.mohamed@ntnu.no

${ }^{1}$ Norwegian University of Science and Technology, Teknologiveien 22, 2815

Gjøvik, Norway

Full list of author information is available at the end of the article
}

a study and modeling of WBAN channel characteristics important [2].

Most of the existing studies on on-body, off-body, and body-to-body channels are based on measurements [3-5]. For on-body channels, measurements were conducted in [3] at four locations using seven receivers and a transmitter attached on the body. Autocorrelation and crosscorrelation functions were reported, and the data collected were used to develop models for fading in various on-body links. Similar studies were conducted in [6] in the frequency range of $3-5 \mathrm{GHz}$ and in [7] for ultrawideband 3.1-10.6 GHz. In [8], the effect of antenna polarization with respect to the body surface was examined, while in [9], the comparison for three locations of the hub on the human was conducted.

For off-body channels, path loss was modeled in [4] from the measurement conducted in an anechoic chamber, while in [2], the measurements were conducted in an indoor environment. The lognormal distribution proved to be a good fit in describing normalized signal amplitude in both. As in [8], the impact of antenna polarization on off-body channel characteristics was studied in [10], and the importance of off-body diversity gain for various off- 
body channels was investigated in [11]. Further in [12], measurement conducted using multiple-input-multipleoutput antennas showed improvement on the reliability of the off-body channels. A methodology for determining the optimal positions of these antennas independent of the frequency was presented in [13].
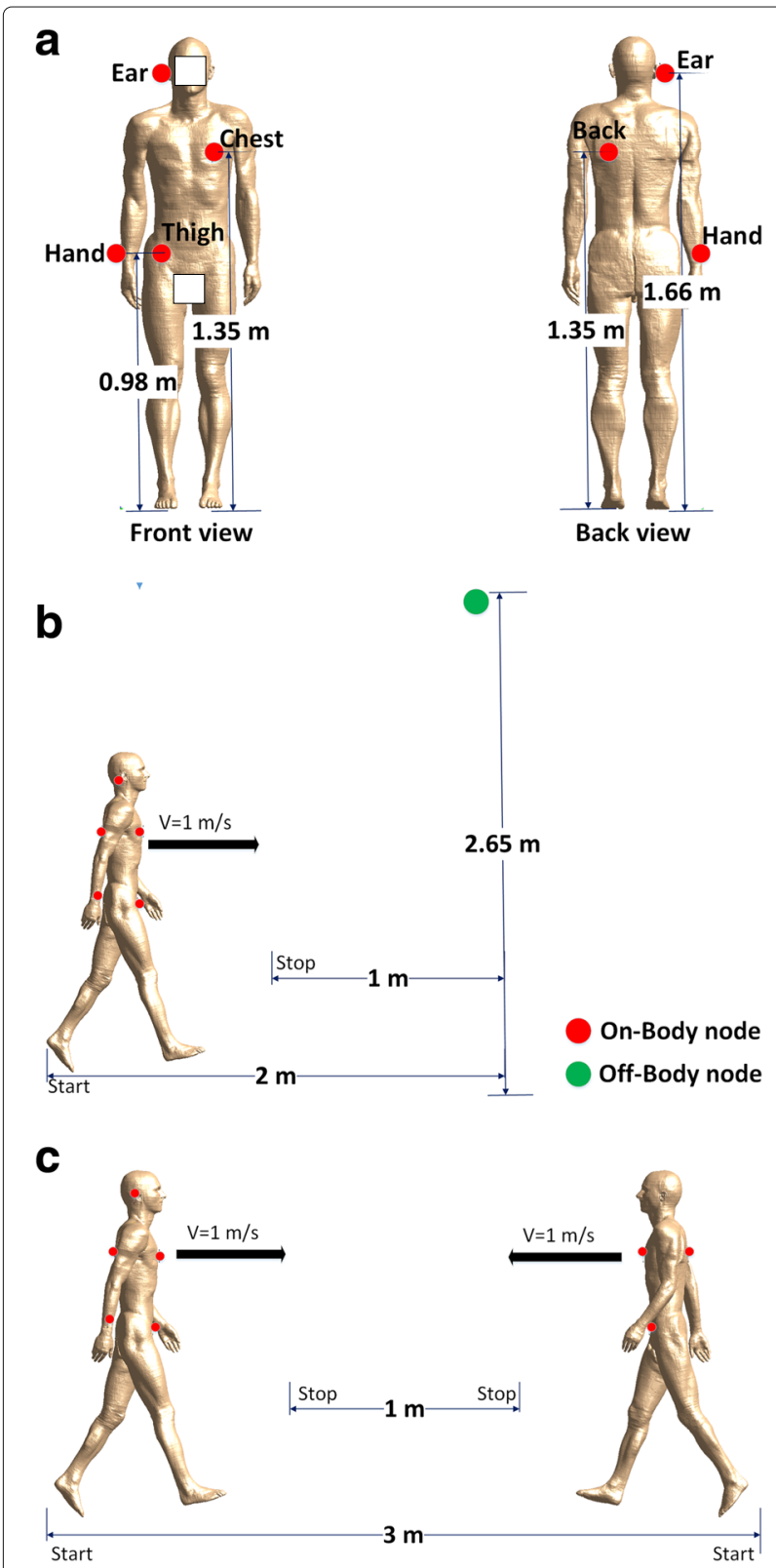

Fig. 1 The investigated scenarios. a Location of on-body nodes on the human model. In scenario 1, a subject walks with on-body nodes attached. b Scenario 2 (off-body). A subject walking with on-body nodes attached, towards the off-body node at a velocity of $1 \mathrm{~m} / \mathrm{s}$. c Scenario 3 (body-to-body). Two subjects with on-body nodes attached, walking at a velocity of $1 \mathrm{~m} / \mathrm{s}$ towards each other. The ear and hand nodes are not visible on the subject on the right
For body-to-body channels, a study in [5] investigated the impact of users' body rotation, tilting, walking in the line of sight (LOS), and non-line-of-sight conditions on the outdoor body-to-body channels. A similar study in an indoor environment was conducted in $[14,15]$ and at the ultrawideband frequency of $2-8 \mathrm{GHz}$ in [16]. The studies highlighted how the movement affected the channel dynamic properties. This was confirmed by the study in [17] which was conducted in both indoor and outdoor environments to obtain the mean path loss and the standard deviation for different body motion scenarios and antenna placements. As in [12], a diversity combining scheme was investigated in [18] and has shown some promising results.

Since the aforementioned models are applicable for a particular measurement setup, other researchers have tried to use physical models instead [19, 20]. These models are based on calculation of time-varying shadowing effects of human body movement and the addition of multipath component using statistical distribution depending on the location. Another approach is the use of numerical simulations such as finite-difference time-domain (FDTD) [21-24]. In [24], a walking phantom created by animation software is used for simulating the time-varying on-body communication channel in which mean path loss was investigated. A similar study was conducted in [23] to represent in addition the delay properties of the channels, and a study focusing on ultrawideband was conducted in [22]. The studies which apply FDTD have so far been limited to static on-body network channels, using a homogeneous phantom [21, 24], with low time resolution [22]. This does not cover the dynamic behavior from the off-body and body-to-body channels, which require a high time resolution, and the use of heterogeneous phantom to be more realistic.

Table 1 Simulation parameters for on-body, off-body, and body-to-body scenarios

\begin{tabular}{ll}
\hline Parameter & Value \\
\hline Software & Sim4Life, Poser \\
Human model & $\begin{array}{l}\text { Duke Model (height } 1.77 \mathrm{~m} \text {, } \\
\text { weight 70.2 kg) [25] }\end{array}$ \\
Walking model & Thalmann model [28] \\
Antenna & Dipole \\
Frequency & $2.45 \mathrm{GHz}$ \\
Antenna separation & $5 \mathrm{~mm}$ \\
Sampling rate & $50 \mathrm{~Hz}$ \\
On-body node locations & Right ear, left chest, right thigh, \\
right hand, left back
\end{tabular}



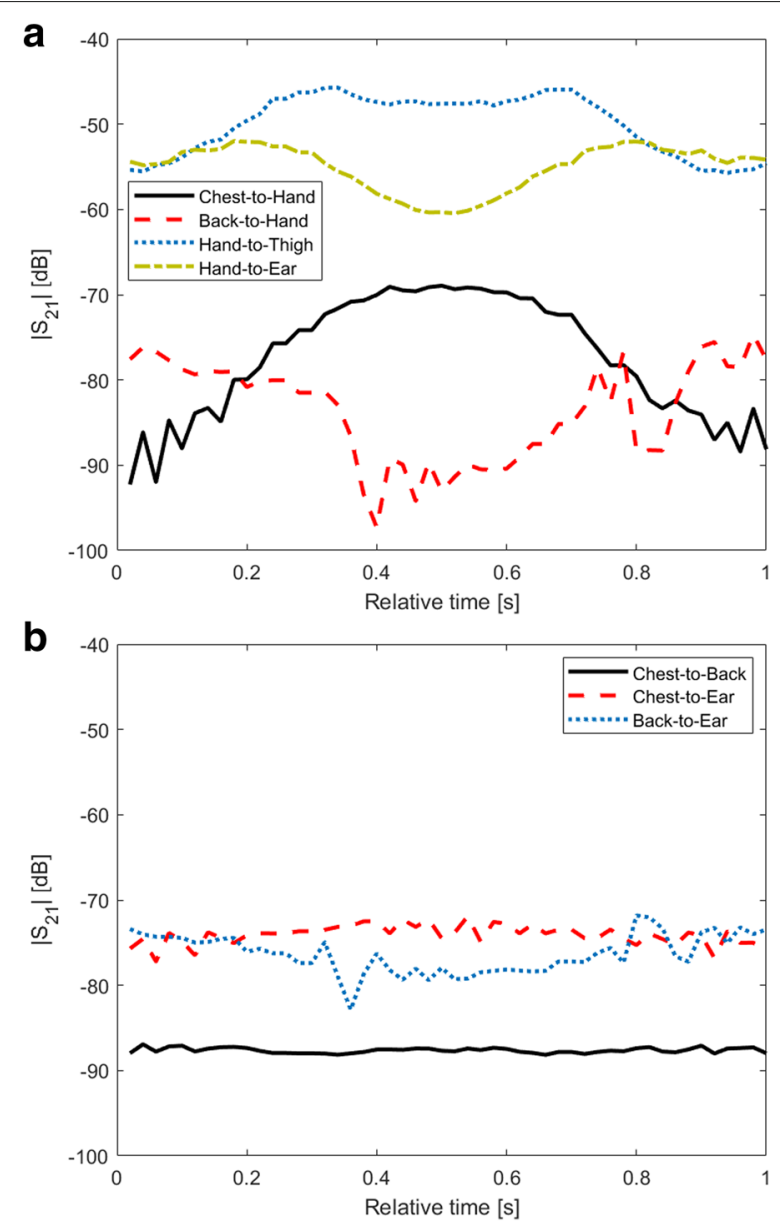

Fig. 2 Time series of simulated data for on-body channels. a Hand channels. b Channels which do not involve the hand or thigh antenna
The novelties of this study are as follows:

- The on-body, off-body, and body-to-body dynamic channels are investigated together in the same conditions so that a more complete picture of the overall network can be observed and compared.

- The study makes use of heterogeneous phantom and uses time resolution of 50 frames per second to increase the accuracy of the data obtained.

- The channel gain is separated into path loss and antenna gain; this cannot be achieved through measurements since the body is within the near field of the antenna.

- The study investigates the correlation between the channels and the application of multivariate normal distributions in the modeling of WBAN channels. This could enable the modeling of a network of multiple channels jointly, instead of using separate models for separate channels

The rest of this paper is organized as follows: Section 2 describes the methodology used in configuration and data analysis, Section 3 discusses the obtained FDTD simulation results, and Section 4 concludes the paper.

\section{Methodology}

This section describes the scenarios used to analyze different aspects of on-body, off-body, and body-to-body communication channels. The surrounding environment was not included in the simulations, so that the effect of the body on the radio channels can be obtained independent to the other factors. It also describes the method to analyze the results.

\subsection{Scenarios}

Employing FDTD, a heterogeneous human model of height $1.77 \mathrm{~m}$ and weight $70.2 \mathrm{~kg}$ (Duke Model) [25]

Table 2 Average channel gain and standard deviation of on-body channels

\begin{tabular}{|c|c|c|c|c|c|c|c|c|c|}
\hline \multirow[t]{3}{*}{ Number } & \multirow[t]{3}{*}{ Channel name } & \multicolumn{2}{|c|}{ Propagation } & \multicolumn{2}{|c|}{ TX antenna } & \multicolumn{2}{|c|}{ RX antenna } & \multicolumn{2}{|l|}{ Overall } \\
\hline & & Mean & STD & Mean & STD & Mean & STD & Mean & STD \\
\hline & & {$[\mathrm{dB}]$} & {$[\mathrm{dB}]$} & {$[\mathrm{dB}]$} & {$[\mathrm{dB}]$} & {$[\mathrm{dB}]$} & {$[\mathrm{dB}]$} & {$[\mathrm{dB}]$} & {$[\mathrm{dB}]$} \\
\hline 1 & Chest-to-back & -29.97 & 0.31 & -28.17 & 0 & -29.49 & 0 & -87.63 & 0.31 \\
\hline 2 & Chest-to-hand & -37.31 & 6.62 & -23.93 & 3.38 & -13.80 & 2.61 & -75.04 & 7.11 \\
\hline 3 & Chest-to-thigh & -28.36 & 2.01 & -20.96 & 0 & -19.12 & 1.62 & -68.44 & 1.88 \\
\hline 4 & Chest-to-ear & -34.70 & 1.14 & -19.61 & 0 & -19.69 & 0 & -74.00 & 1.14 \\
\hline 5 & Back-to-hand & -42.27 & 4.24 & -25.19 & 3.05 & -14.42 & 4.40 & -81.88 & 5.89 \\
\hline 6 & Back-to-thigh & -38.67 & 7.30 & -30.51 & 0 & -27.59 & 1.17 & -96.77 & 6.66 \\
\hline 7 & Back-to-ear & -43.43 & 2.29 & -20.95 & 0 & -11.66 & 0 & -76.03 & 2.29 \\
\hline 8 & Hand-to-thigh & -20.38 & 4.01 & -15.34 & 3.57 & -13.57 & 2.24 & -49.30 & 3.54 \\
\hline 9 & Hand-to-ear & -28.77 & 3.41 & -12.04 & 1.17 & -13.89 & 1.78 & -54.69 & 2.70 \\
\hline 10 & Thigh-to-ear & -35.01 & 3.36 & -22.01 & 2.59 & -19.31 & 0 & -76.34 & 4.92 \\
\hline
\end{tabular}


was used to represent a male adult human body. A half wavelength antenna (dipole) with a resonance frequency of $2.45 \mathrm{GHz}$ was used as a radiating element for a single tone signal at the same frequency. This frequency was chosen to fit with the Wi-Fi technology that is often present in the indoor environment. The antenna was positioned $5 \mathrm{~mm}$ away parallel to the body to reduce the effect of the body on the radiation pattern of the antenna [26]. This separation is small enough for realistic applications. The antenna type and configuration were the same for all simulation scenarios. We simulated 50 frames of Duke walking $1 \mathrm{~m}$ per $1 \mathrm{~s}$ (velocity $1 \mathrm{~m} / \mathrm{s}$ ), in order to grasp not only the slow fading caused by shadowing but also the fast fading effects caused by body reflection, diffraction, and scattering involved in these dynamic channels [27]. The orientation of the body parts in these frames was estimated using the Thalmann model [28] and was applied to the phantom using Poser software [29]. For each frame, software capable of conducting FDTD calculations (Sim4Life) was set to calculate for each antenna, radiation pattern, and the gain at their current location. Due to the close proximity of the antenna to the human body, the radiation pattern and hence the gain are not similar to those of free space. Further, the software was set to calculate $S_{21}$ parameter between all the nodes available on a given scenario [30]. During calculation, a grid of $2 \mathrm{~mm}$ was used on the phantom which is equivalent to $\lambda / 60$ at the $2.45-\mathrm{GHz}$ center frequency. This makes the limitations imposed by discretization of the round surface of the phantom negligible. Three scenarios were considered as shown in Fig. 1.

- Scenario 1 (on-body), where the subject walks with on-body nodes attached (Fig. 1a)

- Scenario 2 (off-body), where the subject walks towards an off-body node (Fig. 1b)

- Scenario 3 (body-to-body), where two subjects walk towards each other (Fig. 1c)

The same wearable antenna placements (Fig. 1a) were considered in all three simulated scenarios. Table 1 summarizes the parameters used in the FDTD simulations of the given scenarios.

For the on-body scenario, on-body nodes were placed at five different locations on the human body (Fig. 1a). The node positions were chosen with regard to possible medical and non-medical applications. For example, the node on the ear emulates hearing aid instrument, the node on the thigh represents a possible location for a smartphone, the hand represents a fitness tracker, etc. [31]. In addition to this, the node at the back is added as a possible space diversity node for off-body communication where human body shadowing could be significant [18]. This represents the on-body part of the network.
For the off-body scenario, an off-body node located at a height of $2.65 \mathrm{~m}$ was considered in addition to the onbody nodes (Fig. 1b). The location of the off-body node at such height represents Wi-Fi routers, commonly placed
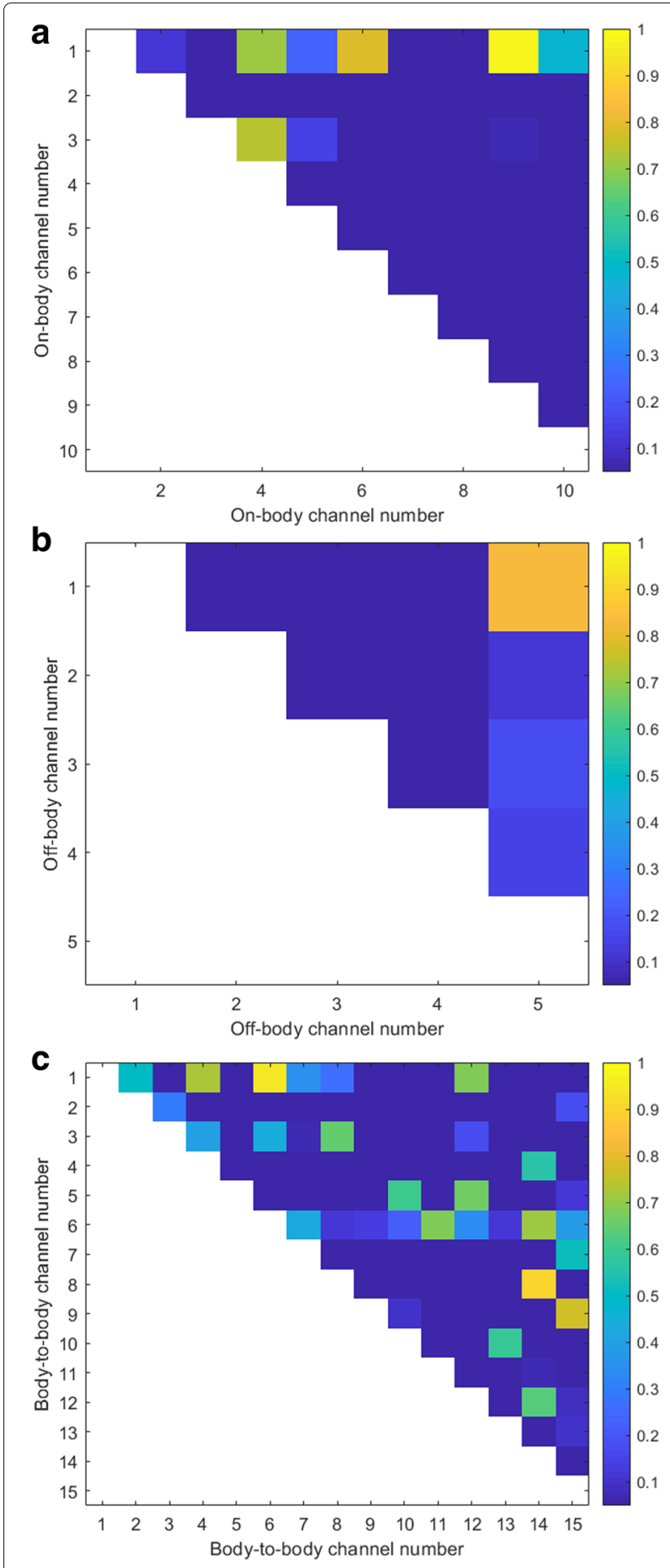

Fig. 3 Correlation significance test. Dark blue indicates significant correlation with $p<0.05$. a On-body channels. b Off-body channels. c Body-to-body channels 
on the ceiling in an indoor environment. The simulation starts at a horizontal distance of $2 \mathrm{~m}$ between the subject and the off-body node to capture the effect of being in close proximity to such an elevated antenna.

For the body-to-body scenario, two identical subjects (Duke) with identical on-body nodes were used for the simulations (Fig. 1c). The subjects were set to walk towards each other, starting from a distance of 3 to $1 \mathrm{~m}$ representing one walking circle for each. The study in this close proximity is important not only for typical bodyto-body network applications [15], but also for the study of inter-on-body network interference [32] and inter-onbody network cooperation [33].

\subsection{Data analysis}

A total of $30 S_{21}$ parameters were obtained from the simulations, in which 10 were for on-body channels, 5 for off-body, and 15 for body-to-body channels. The parameters were then used to give insight on channel fading variations with time and distance. The parameters were also used to analyze the correlation of different channels and the use of multivariate normal distribution in describing the channel amplitudes.

\subsubsection{Fading variation}

The amount of fading a specific WBAN channel experiences depends on the location of its two end nodes on the human body, and the fading variation depends on relative movements of the body parts on which these nodes are located. The close proximity of the antennas to the body affects the overall radiation of the signal [26], and the movements of body parts may also lead to a periodic change of the direction of maximum radiation and hence the gain in the direction of communication [34]. In addition, radio wave propagation is significantly attenuated by human body tissue, and hence, penetration through the body is negligible. The movement of body parts may also cause periodic shadowing to the channel. The $S_{21}$ parameter can be expressed in terms of antenna gain, and the propagation losses as

$$
S_{21}[\mathrm{~dB}]=P_{L}[\mathrm{~dB}]+G_{T X}[\mathrm{dBi}]+G_{R X}[\mathrm{dBi}]
$$

where $P_{L}$ is the propagation loss and $G_{T X}$ and $G_{R X}$ are the transmitting and receiving antenna gains in the direction of communication, taking into consideration the proximity to the human body. With no cables involved in the simulation, $S_{21}$ parameter can be interpreted as the overall channel gain as it is the ratio between the received signal at the receiver port and the transmitted signal at the transmitter port.

\subsubsection{Amplitude distribution}

One of the approaches of modeling potential correlated channels is by using multivariate normal distribution given by [35]

$f(x, \mu, \Sigma)=\frac{1}{\sqrt{|\Sigma|(2 \pi)^{N}}} \exp \left\{-\frac{1}{2}(x-\mu) \Sigma^{-1}(x-\mu)^{\prime}\right\}$

where $N$ is the number of channels being modeled together, $\mu$ is $1 \times N$ matrix containing the channels' means, and $\Sigma$ is the $N \times N$ covariance matrix. Multivariate normal distributions are relatively easy to work with especially in a network with multiple channels. However, this is only applicable when the channels to be considered show a significant correlation which is indicated by the large correlation coefficient and can be confirmed with low $p$ values $(<0.05)$. Pearson's method was used to find the linear correlation coefficient between the channels, and their corresponding $p$ values were calculated using Student's $t$ distribution [36]. Further, the estimated distribution was compared with the simulated data using two-sample Kolmogorov-Smirnov test (KS test) at 0.05 significant level to quantify the goodness of the fit [37].

\section{Results and discussions}

In this section, the results obtained from the simulations described in Section 2 are presented. The results for each scenario are presented separately, and when appropriate,

Table 3 Covariance matrix $\Sigma$ for on-body channels $\left(\times 10^{-9}\right)$

\begin{tabular}{llllllllll}
\hline 0.0022 & -0.0394 & -0.03907 & 0.0020 & 0.0117 & 0.0007 & 0.0213 & -0.9190 & 0.0029 & 0.0156 \\
-0.0394 & 13.7279 & 3.5024 & 2,0961 & -4.4469 & 1.1376 & -3.9243 & 120.5754 & -47.5976 & 8.5976 \\
-0.03907 & 3.5024 & 5.6366 & 0.0917 & -0.7241 & 0.2386 & -1.2142 & 50.1142 & -9.4664 & 1.9884 \\
0.0020 & 2.0961 & 0.0917 & 0.6442 & -0.7345 & 0.1656 & -0.6702 & 19.79063 & -6.4854 & 0.9994 \\
0.0117 & -4.4469 & -0.7241 & -0.7345 & 2.1490 & -0.36736 & 1.0777 & -38.8186 & 14.2770 & -2.6643 \\
0.0007 & 1.1376 & 0.2386 & 0.1656 & -0.3674 & 0.1231 & -0.3030 & 7.0338 & -5.1940 & 0.8827 \\
0.0213 & -3.9243 & -1.2142 & -0.6702 & 1.0777 & -0.3030 & 1.6979 & -38.4941 & 12.8211 & -2.1676 \\
-0.9190 & 120.5754 & 50.1142 & 19.7906 & $-38,8186$ & 7.0338 & -38.4941 & 1525.4063 & -258.5792 & 44.2089 \\
0.0029 & -47.5976 & -9.4664 & -6.4854 & 14.2770 & -5.1940 & 12.8211 & -258.5792 & 251.42130 & -40.0852 \\
0.01562 & 8.5976 & 1.9884 & 0.9994 & -2.6643 & 0.8827 & -2.1676 & 44.2089 & -40.0852 & 10.0612 \\
\hline
\end{tabular}


they are compared. The channels are described by their antenna location, for example, a channel between a ceiling node and a hand node is called ceiling-to-hand.

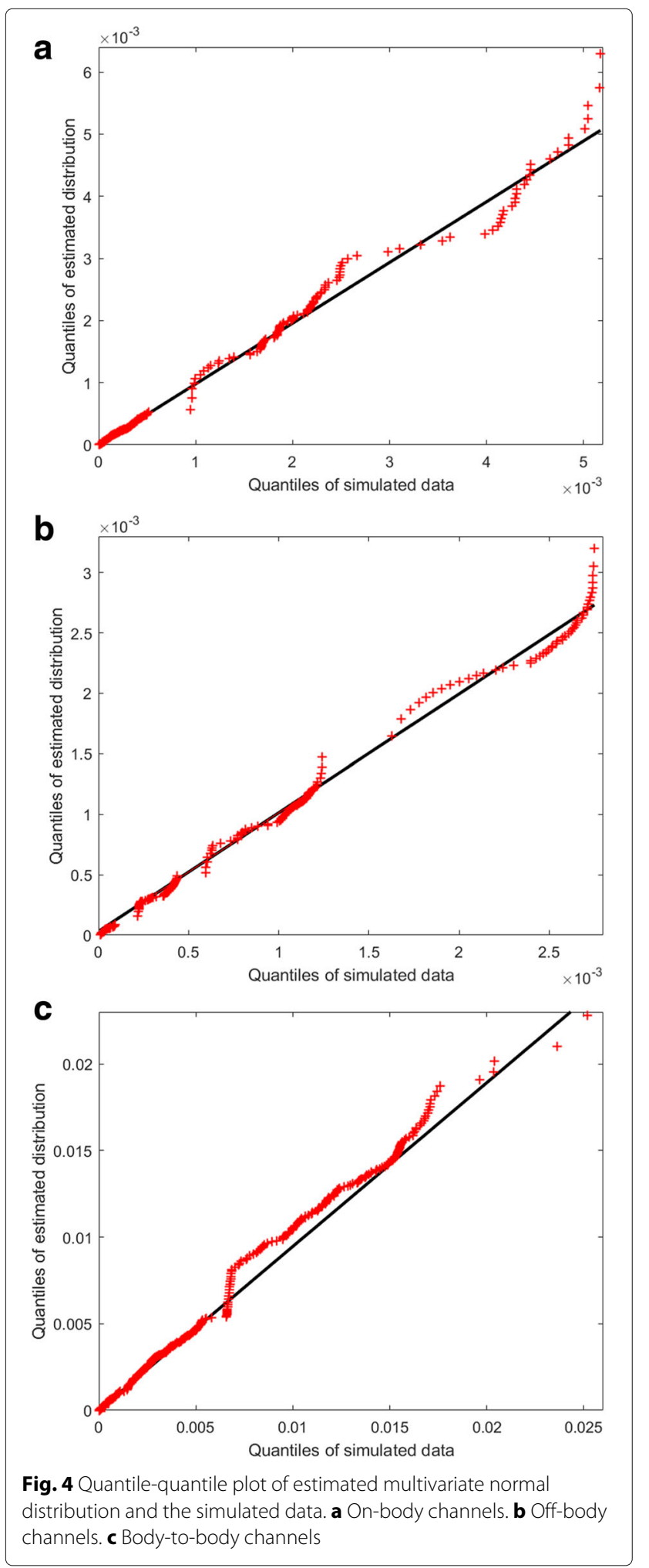

\subsection{On-body channels}

\subsubsection{Fade variation}

The results of the fade variation for the considered onbody channels are summarized in Fig. 2 and Table 2. As expected, the time series (Fig. 2) show a larger variation for the channels involving the nodes located at the hand and the thigh, than for the other channels. This is related to variation in shadowing, as these body parts move from one location to the other during walking. The largest variation of channel gain is obtained on the chest-to-hand channel $(7.11 \mathrm{~dB})$, as the hand moves from the shadowed region to the LOS. The variations are contributed by both, propagation loss and antenna gain. The channel that is least effected by movement of body parts during walking is the chest-to-back channel as confirmed by the lowest standard deviation (STD) of $0.31 \mathrm{~dB}$. The largest average channel gain is obtained for the hand-to-thigh channel $(-49.3 \mathrm{~dB})$. The channel has the shortest distance

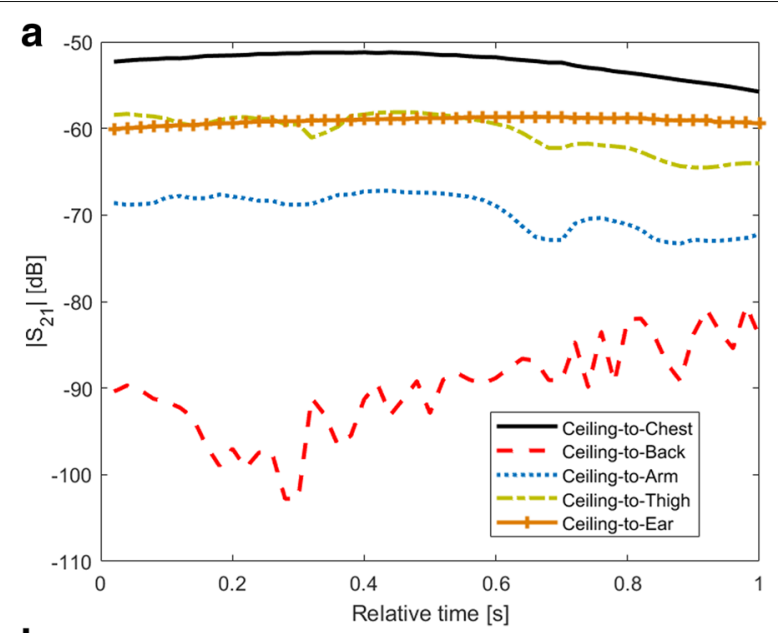

b

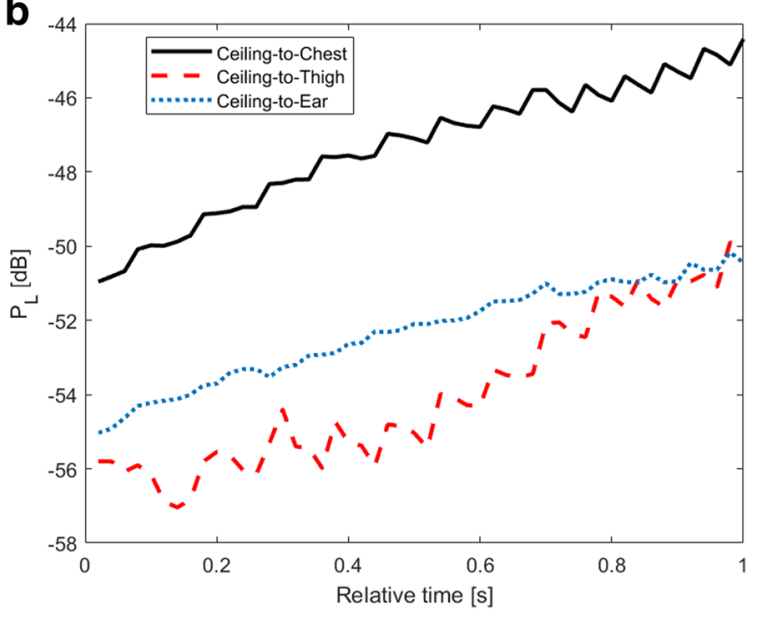

Fig. 5 Time series of simulated data for off-body channels. a Overall channel gain. b Propagation gain 
Table 4 Average channel gain and standard deviation of off-body channels

\begin{tabular}{|c|c|c|c|c|c|c|c|c|c|}
\hline \multirow[t]{3}{*}{ Number } & \multirow[t]{3}{*}{ Channel name } & \multicolumn{2}{|c|}{ Propagation } & \multicolumn{2}{|c|}{ TX antenna } & \multicolumn{2}{|c|}{ RX antenna } & \multicolumn{2}{|l|}{ Overall } \\
\hline & & Mean & STD & Mean & STD & Mean & STD & Mean & STD \\
\hline & & {$[\mathrm{dB}]$} & {$[\mathrm{dB}]$} & {$[\mathrm{dB}]$} & {$[\mathrm{dB}]$} & {$[\mathrm{dB}]$} & {$[\mathrm{dB}]$} & {$[\mathrm{dB}]$} & {$[\mathrm{dB}]$} \\
\hline 1 & Ceiling-to-chest & -47.65 & 1.78 & -1.89 & 1.30 & -2.79 & 1.53 & -52.33 & 1.32 \\
\hline 2 & Ceiling-to-back & -54.15 & 3.89 & -1.10 & 0.96 & -33.42 & 4.00 & -88.67 & 5.37 \\
\hline 3 & Ceiling-to-hand & -60.84 & 0.82 & -2.65 & 1.16 & -5.90 & 1.10 & -69.39 & 2.31 \\
\hline 4 & Ceiling-to-thigh & -54.69 & 2.07 & -3.25 & 1.47 & -2.29 & 2.76 & -60.24 & 2.17 \\
\hline 5 & Ceiling-to-ear & -52.38 & 1.34 & -0.22 & 0.85 & -6.49 & 0.29 & -59.09 & 0.37 \\
\hline
\end{tabular}

between the end nodes and least body shadowing as confirmed by the propagation loss $(-15.89 \mathrm{~dB})$. The smallest average channel gain is obtained for the back-to-thigh channel $(-96.77 \mathrm{~dB})$ contributed by small propagation loss and antenna gain.

\subsubsection{Amplitude distribution}

To confirm the use of a multivariate normal distribution in the estimation of the amplitude distribution, the channels have to be tested for correlation significance. Figure 3a shows the $p$ values of the considered on-body channels, with $80 \%$ of the channels having $p<0.05$, indicating a significant correlation between them. Since the channels show significant correlations, a multivariate normal distribution given by (2) can be used to estimate the amplitude distribution. The estimated covariance matrix is given in Table 3. To evaluate the goodness of the fit, a quantile-quantile plot of the estimated multivariate normal distribution of all 10 on-body channels against the simulation results is shown in Fig. 4a. The plot approximately coincides with the identity line, meaning that the estimated distribution is a good fit of the simulated data. The KS test confirms that the two datasets are from the same distribution with asymptotic $p=0.2178$ and test statistic $k s 2 s t a t=0.0468$.

\subsection{Off-body channels \\ 3.2.1 Fade variation}

The results of the fade variation for the considered offbody channels are summarized in Fig. 5 and Table 4 . The results show overall stable channels with exception from the ceiling-to-back channel (Fig. 5a). This is because in the absence of LOS, the resulting power received is a summation of reflected and diffracted fields, resulting in constructive and destructive interference as the subjects move from one location to another. We also notice the overall increase in the channel gain with time as back node moves out of the shadow region as the subject gets closer to the off-body node. This is not the case for the other channels as they are affected by the change in elevation angle and hence the antenna gain in the direction of communication. There is, however, an overall decrease in propagation loss for these channels (ceiling-to-chest, ceiling-to-thigh, ceiling-to-ear) as the subject gets closer to the off-body node as shown in Fig. 5b.

\subsubsection{Amplitude distribution}

Similar to the on-body channels, the off-body channels were tested for correlation significance so that a multivariate normal distribution could be used to estimate the amplitude distribution of the channels. Figure $3 \mathrm{~b}$ shows the $p$ values of the considered off-body channels, with $60 \%$ of the channels having $p<0.05$, indicating a significant correlation between them. The resulting estimated multivariate distribution's quantile-quantile plot with estimated covariance matrix given Table 5 shows a good fit with simulated data (Fig. 4b). The KS test confirms that the two datasets are from the same distribution with asymptotic $p=0.5982$ and test statistic $k s 2 s t a t=0.0481$.

\subsection{Body-to-body channels \\ 3.3.1 Fade variation}

The results of the fade variation for the considered body-to-body channels are summarized in Table 6. Similar to the off-body channels, the body-to-body channels involving the node located at the back have shown the largest fade variations due to the absence of LOS

Table 5 Covariance matrix $\Sigma$ for off-body channels $\left(\times 10^{-9}\right)$

\begin{tabular}{lllll}
\hline 113.6780 & -5.8442 & 22.4157 & 66.2266 & 0.4873 \\
-5.8442 & 0.4581 & -1.1750 & -3.4201 & 0.2269 \\
22.4157 & -1.1750 & 5.9168 & 15.9113 & -0.7007 \\
66.2266 & -3.4201 & 15.9113 & 49.2340 & -2.1518 \\
0.4873 & 0.2269 & -0.7007 & -2.1518 & 2.1860 \\
\hline
\end{tabular}


Table 6 Average channel gain and standard deviation of body-to-body channels

\begin{tabular}{|c|c|c|c|c|c|c|c|c|c|}
\hline \multirow[t]{3}{*}{ Number } & \multirow[t]{3}{*}{ Channel name } & \multicolumn{2}{|c|}{ Propagation } & \multicolumn{2}{|c|}{ TX antenna } & \multicolumn{2}{|c|}{ RX antenna } & \multicolumn{2}{|l|}{ Overall } \\
\hline & & Mean & STD & Mean & STD & Mean & STD & Mean & STD \\
\hline & & {$[\mathrm{dB}]$} & {$[\mathrm{dB}]$} & {$[\mathrm{dB}]$} & {$[\mathrm{dB}]$} & {$[\mathrm{dB}]$} & {$[\mathrm{dB}]$} & {$[\mathrm{dB}]$} & {$[\mathrm{dB}]$} \\
\hline 1 & Chest-to-chest & -45.70 & 4.05 & 3.30 & 0.19 & 3.30 & 0.19 & -39.09 & 3.7 \\
\hline 2 & Chest-to-back & -57.03 & 9.76 & 3.37 & 0.11 & -30.69 & 0.19 & -84.35 & 9.82 \\
\hline 3 & Chest-to-hand & -46.84 & 4.21 & 3.06 & 0.21 & -6.08 & 0.92 & -49.86 & 3.57 \\
\hline 4 & Chest-to-thigh & -45.09 & 2.58 & 2.67 & 0.64 & 4.36 & 1.99 & -38.06 & 2.02 \\
\hline 5 & Chest-to-ear & -44.94 & 2.32 & 2.79 & 0.60 & -5.07 & 0.50 & -47.22 & 1.66 \\
\hline 6 & Back-to-back & -51.77 & 5.02 & -30.74 & 0.13 & -30.74 & 0.13 & -113.26 & 4.98 \\
\hline 7 & Back-to-hand & -55.84 & 5.63 & -31.52 & 0.82 & -5.94 & 0.76 & -93.30 & 4.83 \\
\hline 8 & Back-to-thigh & -49.91 & 2.57 & -34.21 & 1.31 & 4.51 & 1.77 & -79.60 & 2.98 \\
\hline 9 & Back-to-ear & -53.22 & 3.85 & -28.72 & 0.36 & -4.92 & 0.28 & -86.85 & 4.04 \\
\hline 10 & Hand-to-hand & -46.35 & 1.89 & -8.16 & 1.88 & -8.16 & 1.88 & -62.68 & 2.93 \\
\hline 11 & Hand-to-thigh & -47.28 & 3.47 & -7.73 & 1.80 & 4.28 & 1.58 & -50.73 & 2.40 \\
\hline 12 & Hand-to-ear & -49.28 & 3.35 & -6.79 & 1.52 & -8.32 & 1.80 & -64.39 & 2.57 \\
\hline 13 & Thigh-to-thigh & -47.12 & 3.85 & 4.56 & 1.69 & 4.56 & 1.69 & -39.33 & 2.36 \\
\hline 14 & Thigh-to-ear & -48.72 & 3.11 & 3.52 & 2.63 & -7.74 & 2.15 & -52.93 & 1.83 \\
\hline 15 & Ear-to-ear & -50.54 & 4.65 & -6.26 & 0.82 & -6.26 & 0.82 & -63.06 & 3.44 \\
\hline
\end{tabular}

as indicated by their standard deviation. The channels also have the lowest average channel gain for the same reason. Figure 6 shows the time series of the channels involving the nodes located at the back. The effect of constructive and destructive interference can be seen clearly especially for the chest-to-back and back-to-back channels. On the other hand, the channels which have constant LOS (chest-to-chest, chestto-thigh, and thigh-to-thigh) have the largest average channel gain.

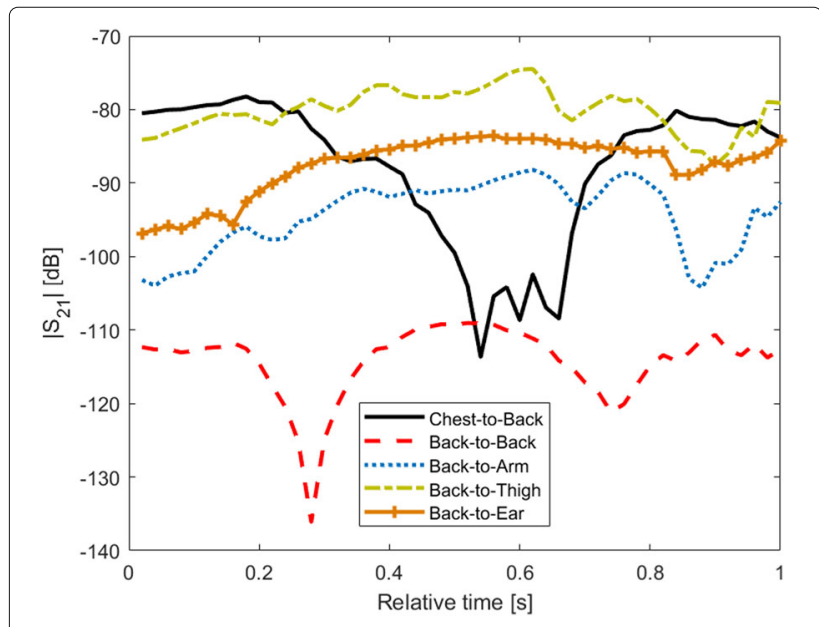

Fig. 6 Time series of simulated data for body-to-body channels

\subsubsection{Amplitude distribution}

The $p$ values of the considered body-to-body channels are shown in Fig. 3c. The results show that $68 \%$ of the channels have $p<0.05$, indicating a significant correlation between the channels; hence, multivariate normal distribution could be used in the estimation of the amplitude distribution of the channels. The resulting estimated multivariate normal distribution's quantile-quantile plot with covariance matrix given in Table 7 is shown in Fig. 4c. The plot approximately coincides with the identity line, meaning the distribution is a good fit of the simulated data. The KS test confirms that the two datasets are from the same distribution with asymptotic $p=0.9037$ and test statistic $k s 2 s t a t=0.0206$

\subsection{Comparison of channels}

The fade variations for on-body channels have shown to depend on the periodic movement of the body part in which the channel nodes are attached. Channels such as chest-to-hand had the largest variation due to the movement of the hand from the shadowed region to the LOS, while chest-to-back channel (on-body) has the least. This is not the case, for off-body and body-tobody channels in which the largest fade variations are shown by those channels with the absence of LOS instead. The ceiling-to-back and chest-to-back channels have the largest fade variations for off-body and body-to-body scenarios respectively. This is because these channels are dominated by constructive and destructive interference 


\begin{tabular}{|c|c|c|c|c|c|c|c|c|c|c|c|c|c|c|}
\hline 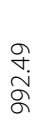 & $\begin{array}{l}\stackrel{ }{+} \\
\infty \\
\infty \\
-\end{array}$ & 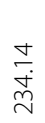 & $\begin{array}{l}\infty \\
\stackrel{\infty}{\sigma} \\
\stackrel{m}{m} \\
1\end{array}$ & \begin{tabular}{l}
$\stackrel{8}{0}$ \\
\multirow{+}{*}{} \\
1
\end{tabular} & 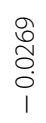 & 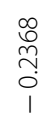 & $\underset{\substack{\tilde{N} \\
1}}{\bar{m}}$ & $\begin{array}{l}\underset{J}{J} \\
\stackrel{0}{0} \\
1 \\
1\end{array}$ & $\begin{array}{l}\stackrel{+}{\infty} \\
\infty \\
\stackrel{n}{n} \\
1\end{array}$ & $\begin{array}{l}\stackrel{\Omega}{0} \\
\stackrel{\dot{H}}{n}\end{array}$ & $\begin{array}{l}\hat{\bar{E}} \\
\stackrel{1}{0}\end{array}$ & $\begin{array}{l}\text { J } \\
\infty \\
\text { Oे }\end{array}$ & 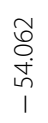 & 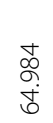 \\
\hline 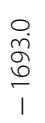 & 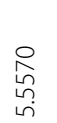 & 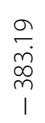 & 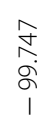 & $\frac{\stackrel{N}{N}}{\stackrel{N}{\sim}}$ & 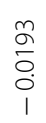 & 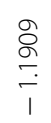 & \begin{tabular}{l}
$\overline{\widetilde{W}}$ \\
\multirow{0}{0}{} \\
1
\end{tabular} & 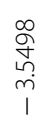 & $\begin{array}{l}\text { fे } \\
\text { के } \\
\infty \\
\text { m }\end{array}$ & $\begin{array}{c}\stackrel{N}{N} \\
\curvearrowright \\
\infty \\
1\end{array}$ & 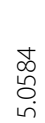 & 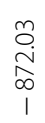 & $\begin{array}{l}\stackrel{\infty}{\sim} \\
\cong \\
\infty \\
\infty\end{array}$ & 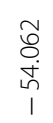 \\
\hline $\begin{array}{l}\infty \\
\equiv \\
\equiv\end{array}$ & $\underset{\substack{\stackrel{2}{N} \\
i}}{\stackrel{N}{i}}$ & $\begin{array}{l}\stackrel{\checkmark}{\alpha} \\
\stackrel{\infty}{\sim}\end{array}$ & $\underset{\stackrel{\infty}{\infty}}{\stackrel{\leftrightarrow}{\hbar}}$ & 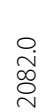 & $\begin{array}{l}0 \\
f \\
\dot{f} \\
0\end{array}$ & $\begin{array}{l}m \\
\stackrel{\infty}{+} \\
\stackrel{\sim}{\sim}\end{array}$ & $\begin{array}{l}\stackrel{u}{0} \\
\stackrel{N}{0} \\
\dot{\infty}\end{array}$ & $\begin{array}{l}\stackrel{m}{m} \\
\stackrel{\sim}{+} \\
\stackrel{\forall}{J}\end{array}$ & 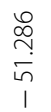 & $\begin{array}{l}\stackrel{0}{\mathrm{~N}} \\
\stackrel{\mathrm{N}}{n}\end{array}$ & 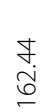 & $\begin{array}{l}\infty \\
\equiv \\
=\end{array}$ & $\underset{\substack{\text { D } \\
1}}{\stackrel{n}{\sim}}$ & $\begin{array}{l}\text { J } \\
\infty \\
\text { O }\end{array}$ \\
\hline $\begin{array}{l}\hat{乏} \\
\frac{\sigma}{\sigma}\end{array}$ & 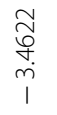 & 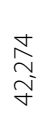 & $\begin{array}{l}\stackrel{\circ}{n} \\
\stackrel{\infty}{\infty} \\
\infty\end{array}$ & $\begin{array}{l}0 \\
\stackrel{0}{0} \\
\stackrel{1}{\infty} \\
\infty\end{array}$ & $\begin{array}{l}\infty \\
\stackrel{\circ}{\circ} \\
\circ \\
\circ\end{array}$ & 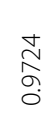 & $\stackrel{\text { ㄱ }}{\stackrel{\mathcal{V}}{\sim}}$ & 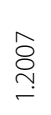 & $\begin{array}{l}\stackrel{\sim}{\approx} \\
\infty \\
\stackrel{N}{N}\end{array}$ & $\begin{array}{l}\stackrel{\bar{\sigma}}{\stackrel{m}{=}} \\
=\end{array}$ & $\begin{array}{l}\underset{N}{\widetilde{v}} \\
\stackrel{\infty}{\sim} \\
\underset{\sim}{n}\end{array}$ & $\begin{array}{l}\underset{f}{\mathbb{Z}} \\
\underset{\sigma}{ }\end{array}$ & 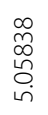 & $\stackrel{\wedge}{\tilde{n}}$ \\
\hline 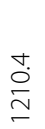 & 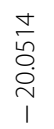 & 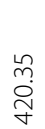 & $\stackrel{\sim}{\stackrel{n}{\sim}}$ & 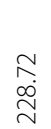 & $\begin{array}{l}\hat{O} \\
\text { ơ } \\
\text { o } \\
1\end{array}$ & 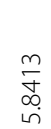 & 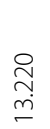 & $\begin{array}{l}\infty \\
\stackrel{n}{2} \\
\tilde{m} \\
\sigma\end{array}$ & 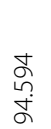 & 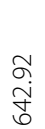 & $\begin{array}{l}\bar{\sigma} \\
\underset{\sigma}{=}\end{array}$ & $\begin{array}{l}\stackrel{ }{1} \\
\text { 은 }\end{array}$ & $\begin{array}{l}\stackrel{n}{N} \\
\underset{\curvearrowright}{\infty} \\
\infty \\
1\end{array}$ & 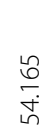 \\
\hline 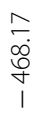 & 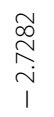 & 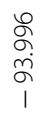 & $\underset{\stackrel{N}{\sigma}}{\stackrel{N}{N}}$ & \begin{tabular}{l}
$\infty$ \\
$\varnothing$ \\
\hdashline \\
\\
\end{tabular} & 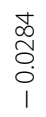 & 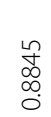 & $\underset{m}{\stackrel{m}{\bar{m}}}$ & 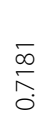 & $\begin{array}{l}\stackrel{m}{\infty} \\
\stackrel{n}{m}\end{array}$ & 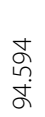 & $\begin{array}{l}\stackrel{n}{n} \\
\infty \\
\stackrel{N}{N}\end{array}$ & 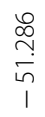 & $\begin{array}{l}o \\
\text { oे } \\
o \\
\infty \\
\text { m. }\end{array}$ & $\begin{array}{l}\stackrel{+}{m} \\
\infty \\
\stackrel{1}{\sim} \\
\text { । }\end{array}$ \\
\hline$\frac{\dot{m}}{\stackrel{m}{m}}$ & $\begin{array}{l}\infty \\
\stackrel{\infty}{n} \\
\stackrel{n}{n} \\
0 \\
1\end{array}$ & $\begin{array}{l}\infty \\
\stackrel{\infty}{+} \\
\sigma \\
\sigma\end{array}$ & $\begin{array}{l}\stackrel{N}{N} \\
\stackrel{m}{m} \\
\end{array}$ & 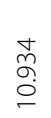 & 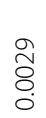 & $\stackrel{\infty}{m} \underset{m}{m}$ & $\begin{array}{l}8 \\
\infty \\
o \\
\\
0\end{array}$ & 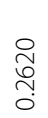 & 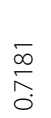 & $\begin{array}{l}\stackrel{2}{\alpha} \\
\text { } \\
\sigma\end{array}$ & 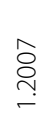 & 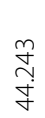 & 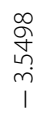 & $\begin{array}{l}\underset{J}{J} \\
\frac{0}{0} \\
1\end{array}$ \\
\hline $\begin{array}{l}\stackrel{\sim}{N} \\
\underset{\dot{v}}{\sim} \\
i\end{array}$ & $\begin{array}{l}m \\
\infty \\
\tilde{m} \\
0 \\
\vdots \\
1\end{array}$ & $\begin{array}{l}\hat{n} \\
\infty \\
\infty \\
i \\
1\end{array}$ & $\begin{array}{l}\text { ๖ } \\
\varnothing \\
\infty \\
1\end{array}$ & $\begin{array}{l}\tilde{L} \\
\mathscr{0} \\
o \\
+ \\
+\end{array}$ & $\begin{array}{l}\text { ర্ } \\
8 \\
0 \\
0\end{array}$ & $\begin{array}{l}\stackrel{\sim}{\Omega} \\
\stackrel{\infty}{0} \\
\stackrel{0}{0}\end{array}$ & 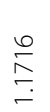 & 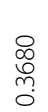 & $\underset{m}{\stackrel{m}{\bar{m}}}$ & $\begin{array}{l}\stackrel{ }{N} \\
\stackrel{m}{n}\end{array}$ & $\underset{\mathcal{F}}{\stackrel{\mathcal{F}}{N}}$ & 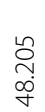 & $\begin{array}{l}\bar{ָ} \\
\stackrel{0}{0} \\
0 \\
1\end{array}$ & 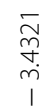 \\
\hline $\begin{array}{l}\stackrel{\wp}{0} \\
\text { ñ. } \\
\end{array}$ & 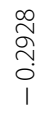 & $\begin{array}{l}m \\
\stackrel{n}{n} \\
\\
m\end{array}$ & 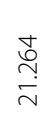 & $\begin{array}{l}\stackrel{n}{\sigma} \\
\stackrel{\sigma}{+} \\
\stackrel{+}{+}\end{array}$ & $\begin{array}{l}\text { ஜे } \\
8 \\
\circ\end{array}$ & $\begin{array}{l}\text { ô } \\
\hat{\sigma} \\
0 \\
0\end{array}$ & 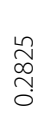 & $\frac{\stackrel{\infty}{m}}{\stackrel{m}{0}}$ & $\begin{array}{l}\text { ñ } \\
\infty \\
\infty \\
0 \\
0\end{array}$ & 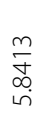 & 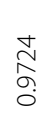 & $\begin{array}{l}\stackrel{n}{m} \\
\stackrel{\infty}{o} \\
\stackrel{0}{\circ}\end{array}$ & $\frac{\stackrel{8}{\circ}}{\stackrel{\circ}{\leftarrow}}$ & 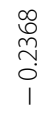 \\
\hline 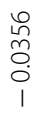 & $\begin{array}{l}0 \\
\bar{\sigma} \\
0 \\
0 \\
1\end{array}$ & $\begin{array}{l}\hat{\sigma} \\
\frac{1}{0}\end{array}$ & $\begin{array}{l}\infty \\
\omega \\
\alpha \\
\alpha \\
0\end{array}$ & 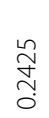 & 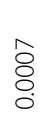 & ஓे & 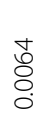 & 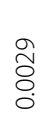 & 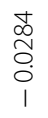 & $\begin{array}{l}\hat{o} \\
\text { Oे } \\
\text { O } \\
1\end{array}$ & $\begin{array}{l}\infty \\
\stackrel{\infty}{\sigma} \\
\delta \\
0\end{array}$ & $\begin{array}{l}\stackrel{0}{f} \\
\underset{\delta}{0} \\
0\end{array}$ & 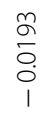 & 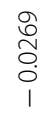 \\
\hline$\frac{\sim}{\stackrel{\sigma}{m}}$ & 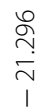 & \begin{tabular}{l}
$\stackrel{\infty}{+}$ \\
$\stackrel{\sim}{\sim}$ \\
\multirow{\sigma}{*}{}
\end{tabular} & $\begin{array}{l}\infty \\
\bar{\sigma} \\
\Sigma\end{array}$ & 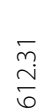 & 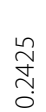 & 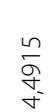 & $\begin{array}{l}\mathscr{8} \\
\mathscr{0} \\
\dot{ \pm}\end{array}$ & 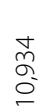 & 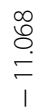 & $\begin{array}{l}\underset{N}{N} \\
\stackrel{\infty}{N} \\
\underset{N}{N}\end{array}$ & 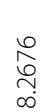 & $\begin{array}{l}\text { O } \\
\text { D } \\
\text { O }\end{array}$ & $\frac{\underset{N}{N}}{\stackrel{N}{I}}$ & $\begin{array}{l}\circ \\
\& \\
+ \\
\dot{7} \\
1\end{array}$ \\
\hline 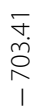 & 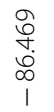 & 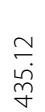 & \begin{tabular}{l}
$\infty$ \\
\multirow{J}{J}{} \\
\end{tabular} & 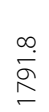 & $\begin{array}{l}\infty \\
\stackrel{n}{n} \\
\stackrel{2}{\sigma} \\
0\end{array}$ & $\begin{array}{l}\text { Ũ } \\
\stackrel{N}{N}\end{array}$ & $\begin{array}{l}\varnothing \\
\varnothing \\
\infty \\
\infty\end{array}$ & $\begin{array}{l}\tilde{N} \\
\stackrel{N}{0} \\
\infty \\
m\end{array}$ & $\begin{array}{l}\hat{\curvearrowright} \\
\stackrel{\sim}{\sim}\end{array}$ & $\stackrel{\stackrel{\sim}{m}}{\stackrel{\sim}{\simeq}}$ & 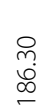 & $\begin{array}{l}\stackrel{0}{\operatorname{n}} \\
\stackrel{\hbar}{\hbar}\end{array}$ & 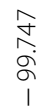 & $\begin{array}{l}\infty \\
\sigma \\
\sigma \\
\bar{n} \\
1\end{array}$ \\
\hline$\underset{\substack{n \\
\hat{n}}}{\stackrel{n}{n}}$ & $\begin{array}{l}\sqrt[i n]{0} \\
\stackrel{0}{N} \\
i\end{array}$ & $\begin{array}{l}0 \\
\stackrel{0}{6} \\
\underline{\sigma}\end{array}$ & $\underset{\stackrel{\sim}{r}}{\stackrel{\sim}{\Psi}}$ & $\begin{array}{l}\stackrel{\infty}{+} \\
\stackrel{\sim}{\sim} \\
\stackrel{f}{*}\end{array}$ & $\begin{array}{l}\hat{\sigma} \\
\bar{\sigma}\end{array}$ & 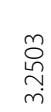 & $\begin{array}{l}\hat{n} \\
\stackrel{0}{0} \\
\stackrel{1}{1} \\
1\end{array}$ & $\begin{array}{l}\infty \\
\stackrel{\infty}{\sigma} \\
\infty \\
\sigma\end{array}$ & 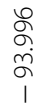 & 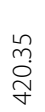 & 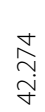 & $\begin{array}{l}\stackrel{+}{\alpha} \\
\stackrel{\text { N }}{\infty}\end{array}$ & 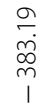 & $\begin{array}{l}\stackrel{\nabla}{ \pm} \\
\underset{\sim}{\sim}\end{array}$ \\
\hline $\begin{array}{l}\frac{\bar{\infty}}{\circ} \\
\frac{\operatorname{O}}{1}\end{array}$ & 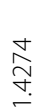 & $\begin{array}{l}\overline{i n} \\
\stackrel{0}{N} \\
i\end{array}$ & 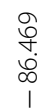 & 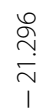 & $\begin{array}{l}\frac{0}{\sigma} \\
\bar{\sigma} \\
0 \\
1 \\
1\end{array}$ & 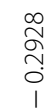 & $\begin{array}{l}m \\
\infty \\
m \\
O \\
0 \\
1\end{array}$ & $\begin{array}{l}\infty \\
\stackrel{\infty}{n} \\
\stackrel{n}{n} \\
0 \\
1\end{array}$ & $\underset{\substack{N \\
\underset{N}{N}}}{\stackrel{\infty}{N}}$ & $\begin{array}{l}\bar{n} \\
\stackrel{5}{0} \\
\stackrel{2}{ } \\
1\end{array}$ & 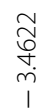 & $\underset{\substack{\stackrel{2}{N} \\
i}}{\stackrel{ }{N}}$ & 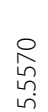 & 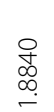 \\
\hline ळे & $\frac{\infty}{\frac{\infty}{\sim}}$ & $\underset{\substack{n \\
i n}}{\stackrel{n}{n}}$ & 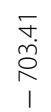 & $\underset{\bar{\sigma}}{\bar{m}}$ & $\begin{array}{l}0 \\
\stackrel{n}{n} \\
O \\
0 \\
0 \\
1\end{array}$ & 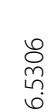 & 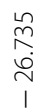 & 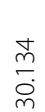 & \begin{tabular}{l}
$\hat{}$ \\
$\infty$ \\
$o$ \\
\multirow{o}{*}{} \\
1
\end{tabular} & 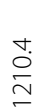 & $\underset{\sigma}{\sigma}$ & $\begin{array}{l}\infty \\
\equiv \\
=\end{array}$ & 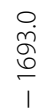 & $\begin{array}{l}\text { ণ্. } \\
\text { ু }\end{array}$ \\
\hline
\end{tabular}


between the reflected and diffracted fields, which vary significantly with distance. For the case of the average channel gain, larger values have been seen in channels with LOS and relatively short distance for on-body (handto-thigh), off-body (ceiling-to-chest), and body-to-body (chest-to-thigh).

The channels for all scenarios showed a significant correlation with $p<0.05$ for $80 \%$ of on-body channels, $60 \%$ of off-body channels, and $68 \%$ of body-to-body channels. This justified the use of multivariate normal distribution in the estimation of the amplitude distribution of the channels. The resulting estimate of amplitude distribution showed a good fit with the simulated data with quantilequantile plots coinciding with the identity line for all the scenarios.

The antenna placements favorable for off-body and body-to-body communications are those that have the least fading and least fade variations. The chest node appears to be more favorable for the off-body communication due to its low and stable fade values (Fig. 5a). However, this is only applicable in the LOS situation when the subject is facing the off-body node. When the subject orientation changes as in the case of a subject moving away from the off-body node, the back node could be the better option. The best practice will then be to alternate between the chest and back node depending on the subject orientation. This can be confirmed by the negative linear correlation between the two channels as shown in Fig. 7a. A similar approach can be taken to exploit spatial diversity from other channels with negative linear correlation in Fig. 7. For the on-body communications, we also notice that the channels involving the back node experience the most fading (Table 2). This implies that in a star topology network, the back node is not a feasible option as the center node.

\section{Conclusion}

In this work, FDTD was used in the investigation of dynamic WBAN channel characteristics during walking. More specifically, the channels considered were 10 onbody, 5 off-body, and 15 body-to-body channels. The channels were investigated in terms of fade variation and their corresponding amplitude distributions. For on-body channels, the fade variation was found to be periodic, with a larger fade variation shown by the channels involving the nodes at the hand and thigh. Off-body and body-to-body channels with the absence of LOS experienced constructive and destructive interference as the distance between the end node changed. This resulted in larger fade variation than the channels involving the nodes at the hand and thigh. For the amplitude distribution of the channels, the multivariate normal distribution was considered. The distribution was considered after the channels show significant correlation between each other. The resulting estimated multivariate distributions fit well the simulated data, for on-body, off-body, and body-to-body channels. This will reduce the complexity of performance analysis of the network.
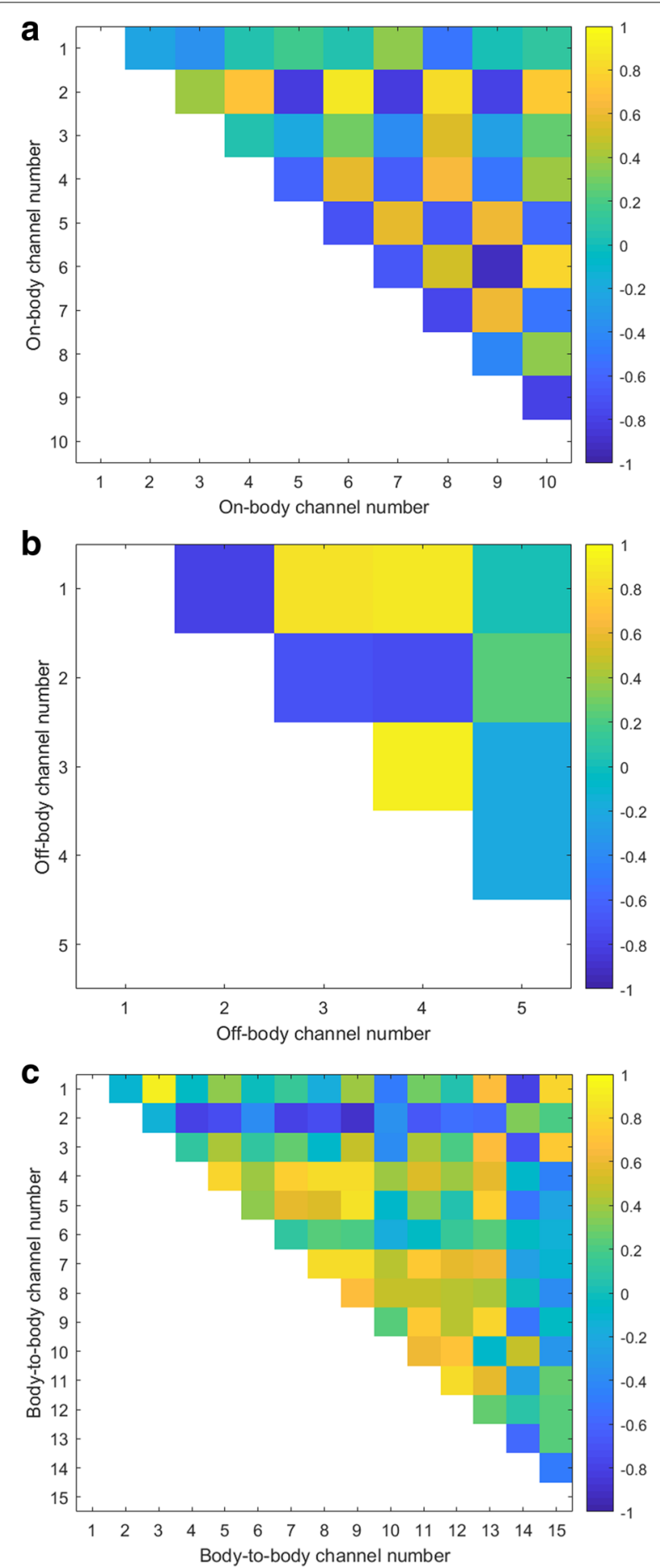

Fig. 7 Pearson correlation coefficient. a On-body channels. b Off-body channels. c Body-to-body channels 


\section{Abbreviations}

FDTD: Finite-difference time-domain; LOS: Line of sight; STD: Standard deviation; WBAN: Wireless body area network

\section{Acknowledgements}

The authors would like to thank the Norwegian University of Science and Technology, Norway, and Ghent University/IMEC INTEC-WAVES for supporting this work.

\section{Funding}

This work was supported by the Ministy of Education and Research, Norway.

\section{Availability of data and materials}

The dataset(s) supporting the conclusions of this article are available in the figshare repository https://figshare.com/articles/Characterization_of_ Dynamic_Wireless_Body_Area_Network_Channels_During_Walking_zip/ 6226949.

\section{Authors' contributions}

MM and WJ identified the channel to be modeled. MM conducted the simulations with GV, analyzed the data with ET, and wrote the manuscript. WJ supported and supervised the research. WJ, GV, ET, and MC proofread the manuscript. All authors read and approved the final manuscript.

\section{Competing interests}

The authors declare that they have no competing interests.

\section{Publisher's Note}

Springer Nature remains neutral with regard to jurisdictional claims in published maps and institutional affiliations.

\section{Author details \\ ${ }^{1}$ Norwegian University of Science and Technology, Teknologiveien 22, 2815 Gjøvik, Norway. ${ }^{2}$ Ghent University/IMEC INTEC-WAVES, iGent - \\ Technologiepark 15, 9052 Gent, Belgium.}

\section{Received: 7 May 2018 Accepted: 25 March 2019}

Published online: 29 April 2019

\section{References}

1. Q. H. Abbasi, M. U. Rehman, K. Qaraqe, A. Alomainy, Advances in Body-Centric Wireless Communication: Applications and State-of-the-Art. (Institution of Engineering and Technology, Stevenage, 2016)

2. D. B. Smith, D. Miniutti, L. W. Hanlen, Characterization of the body-area propagation channel for monitoring a subject sleeping. IEEE Trans. Antennas Propag. 59(11), 4388-4392 (2011)

3. S. L. Cotton, G. A. Conway, W. G. Scanlon, A time-domain approach to the analysis and modeling of on-body propagation characteristics using synchronized measurements at $2.45 \mathrm{GHz}$. IEEE Trans. Antennas Propag. 57(4), 943-955 (2009)

4. S. Cotton, A. McKernan, A. Ali, W. Scanlon, in Proceedings of the 5th European Conference on Antennas and Propagation (EUCAP). An experimental study on the impact of human body shadowing in off-body communications channels at 2.45 GHz (IEEE, 2011), pp. 3133-3137

5. S. L. Cotton, A. McKernan, W. G. Scanlon, in Proceedings of Loughborough Antennas and Propagation Conference (LAPC). Received signal characteristics of outdoor body-to-body communications channels at 2.45 GHz (IEEE, 2011), pp. 1-4

6. R. D'Errico, L. Ouvry, A statistical model for on-body dynamic channels. Int. J. Wirel. Inf. Netw. 17(3-4), 92-104 (2010)

7. D. Goswami, K. Sarma, A. Mahanta, in Proceedings of IEEE International Conference on Signal Processing, Informatics, Communication and Energy Systems (SPICES). Experimental determination of path loss and delay dispersion parameters for on-body UWB WBAN channel (IEEE, 2015), pp. 1-4

8. R. Rosini, R. D'Errico, in Proceedings of Loughborough Antennas and Propagation Conference ( $L A P C)$. Comparing on-body dynamic channels for two antenna designs (IEEE, 2012), pp. 1-4

9. V. Sipal, D. Gaetano, P. McEvoy, M. J. Ammann, Impact of hub location on the performance of wireless body area networks for fitness applications. IEEE Antennas Wirel. Propag. Lett. 14, 1522-1525 (2015)
10. R. Rosini, R. D'Errico, in Proceedings of 6th European Conference on Antennas and Propagation (EUCAP). Off-body channel modelling at $2.45 \mathrm{GHz}$ for two different antennas (IEEE, 2012), pp. 3378-3382

11. Q. H. Abbasi, M. U. Rehman, H. T. Chattha, K. Qaraqe, A. Alomainy, Y. Hao, C. Parini, Ultra wideband antenna diversity characterisation for off-body communications in an indoor environment. IET Microwaves Antennas Propag. 8(14), 1161-1169 (2014)

12. P. Van Torre, L. Vallozzi, C. Hertleer, H. Rogier, M. Moeneclaey, J. Verhaevert, Indoor off-body wireless MIMO communication with dual polarized textile antennas. IEEE Trans. Antennas Propag. 59(2), 631-642 (2011)

13. M. Marinova, A. Thielens, E. Tanghe, L. Vallozzi, G. Vermeeren, W. Joseph, H. Rogier, L. Martens, Diversity performance of off-body MB-OFDM UWB-MIMO. IEEE Trans. Antennas Propag. 63(7), 3187-3197 (2015)

14. R. Rosini, R. Verdone, R. D'Errico, Body-to-body indoor channel modeling at $2.45 \mathrm{GHz}$. IEEE Trans. Antennas Propag. 62(11), 5807-5819 (2014)

15. F. Mani, R. D'Errico, A spatially aware channel model for body-to-body communications. IEEE Trans. Antennas Propag. 64(8), 3611-3618 (2016)

16. T. Kumpuniemi, M. Hämäläinen, K. Y. Yazdandoost, J. linatti, in Proceedings of 9th European Conference on Antennas and Propagation (EUCAP). Measurements for body-to-body UWB WBAN radio channels (IEEE, 2015), pp. 1-5

17. S. J. Ambroziak, L. M. Correia, K. Turbic, in Proceedings of URSI Asia-Pacific Radio Science Conference (URSI AP-RASC). Radio channel measurements in body-to-body communications in different scenarios (IEEE, 2016), pp. 1376-1379

18. S. L. Cotton, W. G. Scanlon, A. McKernan, in Proceedings of 6th European Conference on Antennas and Propagation (EUCAP). Improving signal reliability in outdoor body-to-body communications using front and back positioned antenna diversity (IEEE, 2012), pp. 3393-3396

19. L. Liu, R. D’Errico, L. Ouvry, P. De Doncker, C. Oestges, Dynamic channel modeling at $2.4 \mathrm{GHz}$ for on-body area networks. Adv. Electron. Telecommun. 2(4), 18-27 (2011)

20. M. Mohamed, M. Cheffena, A. Moldsvor, F. P. Fontan, Physical-statistical channel model for off-body area network. IEEE Antennas Wirel. Propag. Lett. 16, 1516-1519 (2017)

21. T. Aoyagi, M. Kim, J.-i. Takada, K. Hamaguchi, R. Kohno, et al., in Proceedings of the 5th European Conference onAntennas and Propagation (EUCAP). Body motion and channel response of dynamic body area channel (IEEE, 2011), pp. 3138-3142

22. Q. Wang, T. Tayamachi, I. Kimura, J. Wang, An on-body channel model for UWB body area communications for various postures. IEEE Trans. Antennas Propag. 57(4), 991-998 (2009)

23. E. Reusens, W. Joseph, B. Latré, B. Braem, G. Vermeeren, E. Tanghe, L. Martens, I. Moerman, C. Blondia, Characterization of on-body communication channel and energy efficient topology design for wireless body area networks. IEEE Trans. Inf. Technol. Biomed. 13(6), 933-945 (2009)

24. M. Gallo, P. S. Hall, Y. I. Nechayev, M. Bozzetti, Use of animation software in simulation of on-body communications channels at $2.45 \mathrm{GHz}$. IEEE Antennas Wirel. Propag. Lett. 7, 321-324 (2008)

25. I. Foundation, Duke. https://www.itis.ethz.ch/virtual-population/virtualpopulation/vip3/duke/. Accessed 7 May 2018

26. L. Roelens, S. Van den Bulcke, W. Joseph, G. Vermeeren, L. Martens, Path loss model for wireless narrowband communication above flat phantom. Electron. Lett. 42(1), 10-11 (2006)

27. D. Smith, J. Zhang, L. Hanlen, D. Miniutti, D. Rodda, B. Gilbert, Temporal correlation of dynamic on-body area radio channel. Electron. Lett. 45(24), 1212-1213 (2009)

28. P. van Dorp, F. Groen, Human walking estimation with radar. IEE Proceedings-Radar, Sonar Navig. 150(5), 356-365 (2003)

29. Modeling Modules Framework: POSER. https://zmt.swiss/sim4life/ framework/poser/. Accessed 7 May 2018

30. ZMT. Z. MedTech, Sim4Life 4.0 User Manual. ZMT Zurich MedTech, Zurich, Switzerland (2018)

31. D. B. Smith, D. Miniutti, T. A. Lamahewa, L. W. Hanlen, Propagation models for body-area networks: a survey and new outlook. IEEE Antennas Propag. Mag. 55(5), 97-117 (2013)

32. M. Alasti, M. Barbi, K. Sayrafian, in Proceedings of 25th Annual International Symposium on Personal, Indoor, and Mobile Radio Communication (PIMRC). Uncoordinated strategies for inter-ban interference mitigation (IEEE, 2014), pp. 2150-2154 
33. J. Dong, D. Smith, in Proceedings of 23rd International Symposium on Personal Indoor and Mobile Radio Communications (PIMRC). Cooperative body-area-communications: enhancing coexistence without coordination between networks (IEEE, 2012), pp. 2269-2274

34. M. Mackowiak, L. M. Correia, A statistical model for the influence of body dynamics on the gain pattern of wearable antennas in off-body radio channels. Wirel. Pers. Commun. 73(3), 381-399 (2013)

35. P. Mukhopadhyay, Multivariate Statistical Analysis. (World Scientific, Singapore, 2009)

36. G. L. Shevlyakov, H. Oja, Robust Correlation: Theory and Applications, vol. 3. (Wiley, Hoboken, 2016)

37. G. W. Corder, D. I. Foreman, Nonparametric Statistics: A Step-by-step Approach. (Wiley, Hoboken, 2014)

\section{Submit your manuscript to a SpringerOpen ${ }^{\circ}$ journal and benefit from:}

- Convenient online submission

- Rigorous peer review

- Open access: articles freely available online

- High visibility within the field

- Retaining the copyright to your article

Submit your next manuscript at $>$ springeropen.com 